\title{
Hydroxyurea in the management of sickle cell disease: pharmacogenomics and enzymatic metabolism
}

\author{
Sètondji Cocou Modeste Alexandre Yahouédéhou ${ }^{1,2}$ • Elisângela Vitória Adorno ${ }^{2}$ Caroline Conceição da Guarda ${ }^{1}$. \\ Uche Samuel Ndidi $^{1}$. Suellen Pinheiro Carvalho ${ }^{1,2}$ - Rayra Pereira Santiago ${ }^{1}$ - Milena Magalhães Aleluia ${ }^{1}$. \\ Rodrigo Mota de Oliveira ${ }^{1,2} \cdot$ Marilda de Souza Gonçalves ${ }^{1,2}$
}

Received: 7 November 2017 / Revised: 20 June 2018 / Accepted: 10 August 2018

(c) Springer Nature Limited 2018

\begin{abstract}
Hydroxyurea (HU) was approved to be used in the treatment of sickle cell disease (SCD) because of its anti-sickling potential. However, there is variability in HU response among SCD patients and this can be due to physiological, socioeconomic, environmental, metabolic and/or genetic factors. The present review focuses on the latter two. Three quantitative trait loci, $H B G 2, B C L 11 A$ and $H M I P$, have been suggested as important markers for HU response. Other genes (ASS1, KLF10, HAO2, MAP3K5, PDE7B, TOX, NOS1, NOS2A, FLT1, ARG1, ARG2, UGT1A1, OR51B5/6, SIN3A, SALL2, SAR1A, UTB, OCTN1, CYP2C9, AQP9, MPO, CYP2E1, and GSTT1) have also been considered. Studies implicate catalase, urease, horseradish peroxidase and enzymes of CYP450 family in HU metabolism. However, little is known about these enzymes. Therefore, further studies are needed to elucidate the metabolic pathway of HU, which will facilitate pharmacogenomic studies and help in identification of candidate genes for predicting HU response.
\end{abstract}

\section{Introduction}

Hydroxyurea (HU), or hydroxycarbamide, is a hydroxylated analogue of urea (Fig. 1; CAS Registry Number, 127-07-1) $[1,2]$, first synthesized in 1869 by Dresler and Stein and later tested in an experimental model in 1928 by Rosenthal, who suggested its myelosuppressive potential [3, 4]. HU has been used to treat myeloproliferative syndromes, particularly chronic myeloid leukemia, polycythemia vera and psoriasis [5, 6], as well as AIDS, since it inhibits DNA synthesis in human immunodeficiency virus type I (HIV-I) by reducing intracellular dNTP levels in activated lymphocytes [7, 8].

$\mathrm{HU}$, due to its anti-sickling potential, was approved in 1999 by the U.S. Food and Drug Administration for the

Marilda de Souza Gonçalves

mari@bahia.fiocruz.br

1 Laboratório de Investigação em Genética e Hematologia Translacional - LIGHT, Instituto Gonçalo Moniz - IGM/ FIOCRUZ, Salvador, Brazil

2 Laboratório de Pesquisa em Anemia - LPA, Departamento de Análises Clínicas, Faculdade de Farmácia, Universidade Federal da Bahia, Salvador, Brazil treatment of sickle cell disease (SCD) in patients with severe clinical profiles [9-11]. The benefits of HU in SCD patients have been attributed to increasing fetal hemoglobin $(\mathrm{HbF})$ levels, which inhibits the polymerization of the variant hemoglobin $\mathrm{S}$, leading to a reduction in the incidence of painful crises, as well as decreased rates of hospitalization, acute chest syndrome, blood transfusion and mortality among SCD patients [6, 9]. HU is also associated with increasing hemoglobin and mean cell volume of red cells; reducing white cell, platelet and reticulocyte counts; in addition to reducing expression of adhesion molecules and release of nitric oxide (NO) $[12,13]$. However, increase in $\mathrm{HbF}$ levels and the clinical response induced by $\mathrm{HU}$ have been variable among different patients, necessitating elevated dosages and increasing toxicity [9, 14]. Differences in responses can be attributed to various factors, including physiological, socioeconomic and environmental factors. However, genetic factors have been considered as some of the most important determinants of variations in drug therapy response and tolerance [15]. Recently, studies in SCD patients showed that in addition to genomic variations within the $\beta$-globin gene $(H B B)$, variants in modifier genes outside $H B B$ are also significantly associated with increase in $\mathrm{HbF}$ levels, and, consequently, HU treatment response [15]. 


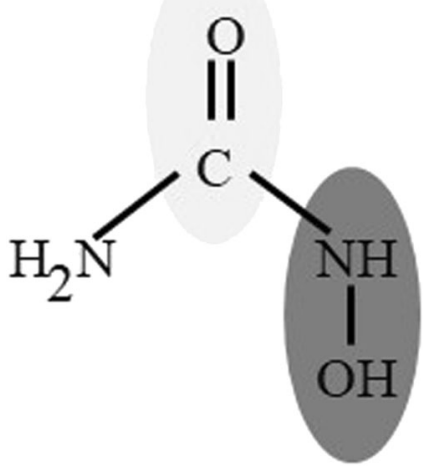

Fig. 1 Chemical structure of hydroxyurea. The areas of hydroxyurea involved in ribonucleotide reductase inhibition and cycling cell killing (grey-shaded area) as well as in nitric oxide production and thereby soluble guanylate cyclase stimulation (black-shaded area) are highlighted. Figure adapted from [17]

Some studies that investigated the enzymatic metabolism of $\mathrm{HU}$, to better understand its mechanism of action, presented experimental evidence suggesting the participation of catalase, urease, horseradish peroxidase and enzymes of the CYP450 family [10, 16]. Pharmacogenomic studies performed later focused on quantitative trait loci (QTL) and modifier genes outside $H B B$, but paid little attention to the genes encoding enzymes that metabolize HU. The present review attempts to summarize findings concerning the genetic factors that influence HU response, such as QTL and the genes that influence $\mathrm{HbF}$ levels, in addition to placing a particular emphasis on genes encoding drug-metabolizing enzymes (DME) and transporters, as well as HU metabolism.

\section{Three models attempting to clarify inter- individual variability in SCD patients on HU}

In 2013, based on some evidence, Banan proposed two models in an attempt to explain the differential HU responses seen in SCD patients: (1) the differential susceptibility model, in which erythroid cells supposedly react differently to $\mathrm{HU}$ in responders and non-responders; (2) the differential baseline $\mathrm{HbF}$ model, in which $\mathrm{HU}$ increases $\mathrm{HbF}$ production in responders and in non-responders, yet only patients with high cellular levels of $\mathrm{HbF}$ respond to HU therapy [17]. In the present review, we propose a third model termed the differential HU metabolism model, in which SCD patients, regardless of their baseline $\mathrm{HbF} \%$, metabolize HU differently irrespective of whether they respond to HU treatment or not (Fig. 2). It is our belief that differences in HU metabolism may provide further insight into the variability observed in patient responses to $\mathrm{HU}$, since it is known that single nucleotide polymorphisms (SNPs) in the genes encoding DME can lead to poor, intermediate, rapid or ultra-rapid $\mathrm{HU}$ metabolism, and, consequently, to differential pharmacokinetics and/or pharmacodynamics [18]. In addition, it was also reported that SNPs within genes encoding DME, transporters or targets could affect therapeutic response in SCD patients, thereby leading to efficacy or toxicity [19].

\section{Biomarkers that affect baseline $\mathrm{HbF}$ levels and influence $\mathrm{HU}$ response}

\section{QTL}

According to the differential baseline $\mathrm{HbF}$ model, genomewide association studies (GWAS) have identified three important QTL associated with baseline $\mathrm{HbF}$ levels in patients with sickle cell anemia (SCA) and $\beta$-thalassemia, as well as in individuals with a normal hemoglobin pattern (HbAA): HBG2, BCL11A (developmental repressor of the $\gamma$-globin gene) and HBSIL-MYB [20-22]. The XmnI $\gamma^{\mathrm{G}}$ polymorphism (rs7482144) $-158 \mathrm{C}>\mathrm{T}$ of the $\gamma^{\mathrm{G}}$-globin (HBG2) gene, located on chromosome 11p15, correlates with higher $\mathrm{HbF}$ levels in $\beta$-thalassemia and SCD patients, leading to decreased disease severity [17, 20, 23]. SNPs (e.g., rs11886868, rs46713993 and rs766432) in the intron 2 of the BCL11A gene located on chromosome 2p16 have been associated with high HbF levels in SCD patients and healthy individuals $[17,23]$. SNPs (e.g., rs9399137 and rs4895441) in the HMIP region between genes HBSIL and $M Y B$, located on chromosome $6 \mathrm{q} 23$, have also been associated with high $\mathrm{HbF}$ levels in SCD patients and healthy individuals $[17,23]$. Wonkam and colleagues found associations between $\mathrm{HbF}$ levels and both BCL11A and HMIP SNPs in Cameroonian SCA patients [24].

Accordingly, it is likely that these QTL affect HbF levels in SCD patients on HU therapy [21,23]. This hypothesis has been corroborated by several studies investigating associations between QTL and elevated levels of $\mathrm{HbF}$ in response to HU. In 2016, Friedrisch and colleagues analyzed Brazilian SCA patients and reported increased endogenous levels of $\mathrm{HbF}$ in association with both $B C L 11 \mathrm{~A}$ and HMIP. Furthermore, BCL11A rs1427407, rs4671393 and rs11886868 were also associated with an increase of 2 to 4 -fold in $\mathrm{HbF}$ level at maximum tolerated dose (MTD) [20]. Banan et al reported a strong correlation of TT genotype of $H B G 2$ and the $\mathrm{C}$ allele of BCL11A rs766432, with HU treatment response observed in Iranian $\beta$-thalassemia patients [25]. Moreover, the $\mathrm{T}$ allele of $H B G 2$ has also been associated with significant increase in hemoglobin $(\mathrm{Hb})$ and $\mathrm{HbF}$ levels, in addition to $\mathrm{HU}$ therapy response in $\beta$-thalassemia intermedia patients, since the results showed that patients carrying the CT genotype presented, after HU therapy, an increase in $\mathrm{Hb}$ and $\mathrm{HbF}$ levels of $0.7 \pm 1.26 \mathrm{mg} / \mathrm{dl}$ 


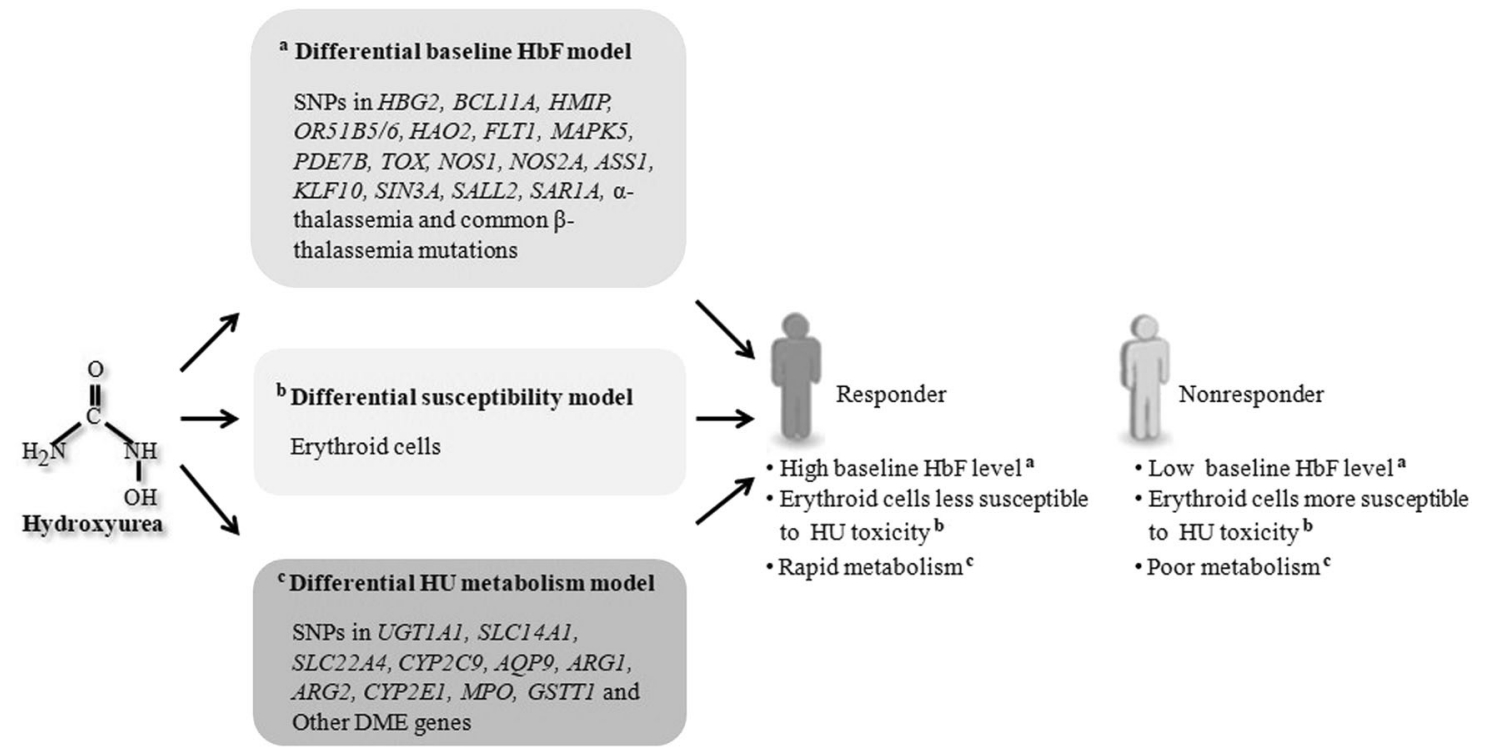

Fig. 2 Models attempting to elucidate differential hydroxyurea responses in SCD patients. Three models are presented, the differential susceptibility model, differential baseline $\mathrm{HbF}$ model and differential HU metabolism model. In the differential susceptibility model, it is supposed that erythroid cells can respond differently to $\mathrm{HU}$ in responders and non-responders. In the differential susceptibility model, the HbF production occurs only in patients with high cellular

and $5.95 \pm 14.8 \mathrm{mg} / \mathrm{dl}$, respectively when compared with those carrying the CC genotype $(0.26 \pm 1.43 \mathrm{mg} / \mathrm{dl}$ and 0.8 $\pm 1.31 \mathrm{mg} / \mathrm{dl}$, respectively) [26]. The TT variant genotype of $H B G 2$ has also been associated with higher $\mathrm{HbF}$ levels both pre and post-HU therapy in Kuwaiti Arab SCD and $\beta$ thalassemia patients on HU [21]. Recently, we found that SCA patients on HU therapy with the CC variant genotype of $B C L 11 A$ rs 766432 presented higher $\mathrm{Hb}$ concentration, red blood cell counts and hematocrit, in addition to lower direct bilirubin level and platelet count [23]. Furthermore, the multivariate linear regression analysis showed an independent and significant contribution of HMIP rs11759553 to modulate $\mathrm{HbF}$ levels.

However, other studies were unable to confirm this association, finding no significant correlations between the $\mathrm{XmnI} \gamma^{\mathrm{G}}$ polymorphism and response to HU [27]. A study carried out in Iranian $\beta$-thalassemic patients also found no significant correlation between the $\mathrm{XmnI} \gamma^{\mathrm{G}}$ polymorphism and HU response [28]. In a study conducted in SCD patients on HU, associations were found between the SNPs in the BCL11A gene (e.g., rs1427407, rs766432, rs4671393, rs7557939, and rs11886868) and baseline HbF\% but none of them showed associations with MTD HbF levels [29]. A study involving Kuwaiti SCD and $\beta$-thalassemia patients on $\mathrm{HU}$ therapy reported that carriers of the $\mathrm{C}$ allele in $B C L 11 \mathrm{~A}$ rs11886868, T allele in HMIP rs9376090, C allele in HMIP rs9399137 and A allele in HMIP rs9402686 had no significant differences in $\mathrm{HbF}$ levels either pre- or post-HU treatment when compared to carriers of respective wild-type levels of HbF. In the differential HU metabolism model, we believe that, HU response will depend on capacity of each patient to metabolize HU. Hence, these three models can together determine the response of SCD patients on HU therapy. SCD patients can have a combination of models. DME drug metabolizing enzyme, SNP single nucleotide polymorphism

alleles [21]. These findings seem to be consistent with the differential HU metabolism model, since no significant increases in $\mathrm{HbF}$ levels were observed in patients on $\mathrm{HU}$ therapy, regardless of whether patients were carriers of $\mathrm{HbF}$ QTL or not. Hence, it appears that in addition to HbF QTL, other genes are involved in the modulation of $\mathrm{HbF}$ production in SCD patients undergoing HU therapy.

\section{Other genes associated with $\mathrm{HbF}$ production and $\mathrm{HU}$ response}

It was reported that the olfactory receptors $(O R)$ genes (OR51B2, OR51B5 and OR51B6), located upstream of the $H B B$ cluster locus control region may regulate the expression of the HBG2 [30-32]. A GWAS performed by Green and colleagues in children with SCD on HU therapy found an association between OR51B6 rs5024042 and baseline $\mathrm{HbF}$ [22]. On the contrary, in a study carried out in Cameroonian SCA patients, nonsignificant association was found between OR51B5/6 rs5024042 and HbF level [24].

In a study carried out on SCA patients that received HU, it was discovered that SNPs within HAO2, MAP $3 K 5$, PDE7B, TOX, NOS1, FLT1, ARG2 and NOS2A were significantly associated with the change of percent and/or absolute $\mathrm{HbF}$. The most significant associations were found between SNP rs2182008 in FLT1, a vascular endothelial growth factor involved in cell proliferation and differentiation, and change of percent $\mathrm{HbF}$ as well as between SNP rs10483801 in ARG2, an enzyme involved in the 
metabolism of drug, and the change of absolute $\mathrm{HbF}$ [14]. In another study involving SCD patients on HU therapy, SNPs $A R G 1$ rs17599586 and ARG2 rs2295644 demonstrated significant associations with increased $\mathrm{HbF}$ levels [29]. A GWAS in hemoglobinopaties patients on HU treatment as well as erythroid progenitor cells from healthy and KLF1-haploinsufficient individuals treated with $\mathrm{HU}$, found a significant association between intronic variants rs9483947 and rs9376230 of MAP3K5, a member of the p38 and the JNK MAPK pathway, and HU response [33].

The Krüppel-like family of transcription factors (KLF1, KLF2, KLF4, and KLF10) is a set of zinc finger DNAbinding proteins that can regulate the $\mathrm{HbF}$ production [34]. Research shows that KLF10 can repress the adult $H B B$ gene interacting with SIN3A, leading to the repression of KLF1 activity, augmentation of $\gamma$-globin synthesis and hence $\mathrm{HbF}$ production [35]. Among the four SNPs identified within the KLF10 gene in white population, it was discovered that KLF10 rs3191333 can be considered as a pharmacogenomic biomarker [36, 37]. A pharmacogenomic study carried out earlier in Hellenic compound $\mathrm{SCD} / \beta$-thalassemia patients as well as healthy and $K L F 1$-haploinsufficient Maltese adults allowed the identification of KLF10 rs3191333 (c.*141C > T) as an important pharmacogenomic biomarker, which facilitate the separation of responders and nonresponders to HU treatment [36]. Recently, in a cross-sectional study performed with Egyptian SCD and $\beta$-thalassemia (major and intermedia) patients on HU therapy, it was also found that KLF1O gene plays a non-stand-alone role as $\mathrm{HbF}$ modifier and can be used as pharmacogenomic biomarker of HU treatment [38]. The participation of SIN3A gene in changes of $H B G 2$ expression was investigated in Hellenic $\beta$-hemoglobinopathies patients and it was found that the intronic SIN3A variants rs11072544 (C> T) and rs7166737 $(\mathrm{T}>\mathrm{C})$ were associated respectively with $\beta$-thalassemia disease severity and $\mathrm{HU}$ treatment response suggesting that they can be considered as pharmacogenomic biomarkers of $\mathrm{HU}$ response [35]. In a prospective study performed in SCA children treated with HU to MTD, Sheehan and colleagues using whole exome sequencing, investigated phenotypegenotype associations and they found out that a coding variant rs61743453 in SALL2 (Spalt-like transcription factor) was associated with higher final $\mathrm{HbF}[39,40]$.

The crucial role of the HU-induced small guanosine triphosphate-binding protein called secretion-associated and RAS-related (SAR) protein in $H B G 2$ induction has been demonstrated [41]. Report showed that some SNPs within the promoter region of SARIA, a gene which acts in hemoglobin regulation, might contribute to the regulation of $\mathrm{HbF}$ expression and modulate the $\mathrm{HU}$ response in the patients [41, 42, 19]. A GWAS carried out in SCD patients identified SNPs in the promoter region of the SAR gene which were associated with the HU response [17].
In a recent study, it was suggested that SNPs (rs10901080 and rs10793902) within the ASS1 gene, located on chromosomal region $9 \mathrm{q} 34$, can serve as pharmacogenomic biomarkers to predict HU treatment efficacy in compound SCD/ $\beta$-thalassemia patients [43]. The G-T-T haplotype derived from the SNPs rs7860909, rs10901080 and rs10793902 was associated with higher $\mathrm{HbF} \%$ and $\mathrm{HU}$ treatment efficacy. Furthermore, the in silico analysis performed by the authors revealed that these markers may induce NO biosynthesis, either altering splicing and/or miRNA binding, which consequently will activate the guanylate cyclase and increase $\gamma$-globin levels [43]. Multivariate analysis performed in SCA patients on HU therapy showed a strong influence of SNPs in ASS and ARGl on the change of $\mathrm{HbF}$ level, suggesting interactions between these genes and other genes for regulating the response to $\mathrm{HU}$ treatment [14].

Specific solute carrier membrane transporters (organic anion-transporting polypeptides-OATPs, cation/carnitine transporters-OCTNs, and urea transporters-UTs) regulate the transcellular traffic and accumulation of $\mathrm{HU}$ in the erythroid cells. The OATPs are more expressed in the intestine, liver and kidneys and associated with modulation of pharmacokinetics of $\mathrm{HU}$, while UTB (encoded by SLC14Al gene) and OCTN1 (encoded by SLC22A4 gene) are expressed principally in erythrocytes and bone marrow [44-46]. Walker and Ofori-Acquah carried out an experimental study which showed that the upregulation of UTB and OCTN1 in erythroid cells correlated with higher HUmediated $H B G 2$ induction suggesting their important role in this process [47]. The result further showed that the OCTN1 expression mediated by $\mathrm{HU}$ was sustained and significantly correlates with $H B G 2$ induction, suggesting the pivotal role of OCTN1 in the efficacy of HU. Furthermore, the SNPs rs12605147 and rs2298720 in UTB demonstrated associations with pharmacokinetic parameters in SCD patients [29]. A GWAS performed in African-American SCA patients on HU therapy included various candidate genes (ARG1, AQP9, ASS, PS1, SLC14A1, LOC57404, POR, $C Y P 2 C 9$, and $C Y P 3 A 5$ ) with a potential role in HU metabolism and genes (RRM1, RRM2, TK1, TYMS, MPO, $S O D 1, A B C B 1$ ) mediating the effect of HU [48]. The results showed associations between SNPs in $C Y P 2 C 9$ and $A Q P 9$, and $\mathrm{HbF}$ response to $\mathrm{HU}$. In a recent study performed in Brazilian SCA patients on $\mathrm{HU}$, we found independent associations between $M P O$ rs 2333227 and total cholesterol, CYP2E1 rs3813867/rs2031920 and alpha 1-antitripsina, null GSTT1 genotype and total bilirubin suggesting that these SNPs can be associated with alterations in lipid, inflammatory and hemolytic profiles, respectively, improving or compromising the treatment of the SCA patients under $\mathrm{HU}$, depending on the SNP and parameter affected [49]. 


\section{SNPs associated with alterations in clinical profile in response to HU therapy}

There is evidence showing that beside factors such as reticulocytes count, frequency of vaso-oclusive events and $\alpha$ thalassemia, genetic variants present in the promoter region of the uridine diphosphate (UDP)—glucuronosyl transferase 1A1 (UGT1A1), the main enzyme responsible for bilirubin conjugation, can be a risk factor for cholelithiasis [50-52]. In SCA patients on HU, an association was found between the $(\mathrm{TA})_{7} /(\mathrm{TA})_{7}$ repeats and higher bilirubin levels [52]. This result was confirmed by Adekile and colleagues that demonstrated that adults SCA patients under HU and carriers of $(\mathrm{TA})_{7} /(\mathrm{TA})_{7}$ repeats had higher levels of bilirubin [53]. Furthermore, a negative correlation was found between $\mathrm{HbF} \%$ and bilirubin levels, suggesting contribution of this genotype in HU response [53]. Research from Italia and colleagues, showed that $(\mathrm{TA})_{7} /(\mathrm{TA})_{7}$ repeats were associated with elevated bilirubin levels among the different groups analyzed (SCA, $\beta$-thalassemia intermedia and $\mathrm{HbE}$ - $\beta$-thalassemia) and the use of HU therapy did not reduce the bilirubin levels under normal values [51]. Furthermore, the results showed that SCA and $\beta$-thalassemia intermedia patients on HU therapy with $(\mathrm{TA})_{7} /(\mathrm{TA})_{7}$ repeats and $\alpha$ thalassemia had higher bilirubin levels in comparison with those without $\alpha$-thalassemia [51]. However, further studies are needed to better understand this interaction between UGTIAl gene promoter polymorphism and HU response.

Report from Panigrahi and colleagues found that heterozygous $\alpha^{3.7}$ deletion carriers responded to HU therapy and were correlated with the $\mathrm{XmnI} \gamma^{\mathrm{G}}$ polymorphism [54]. Hence, they suggested that besides the $\mathrm{XmnI} \gamma^{\mathrm{G}}$ polymorphism, the $\alpha^{3.7}$ deletion can be associated with $\mathrm{HU}$ response in the patients. Genetic correlations between the $\mathrm{XmnI} \gamma^{\mathrm{G}}$ polymorphism and common $\beta$-thalassemia mutations were investigated in different populations and the results were different according to the population studied. A research carried out in Iran showed that $61 \%$ of Iranian transfusion-dependent $\beta$-thalassemia patients on $\mathrm{HU}$ with molecular background favorable to $\mathrm{HU}$ (for example $\mathrm{XmnI} \gamma^{\mathrm{G}}$ polymorphism), strongly associated with the IVSII-I (G- > A) mutation in linkage with the haplotype I [+$-{ }_{-}$] and internal $\beta$-globin framework 2 , shifted from monthly blood transfusion dependency to a stable transfusion-free condition [55]. This result is supported by the works of Alebouyeh and colleagues that found a significant correlation between the $\mathrm{XmnI} \gamma^{\mathrm{G}}$ polymorphism and IVSII-1 mutation [56]. They further demonstrated that the $\mathrm{XmnI} \gamma^{\mathrm{G}}$ polymorphism and IVSII-1 mutation (homo- and/ or heterozygosis) are important markers in most responding major $\beta$-thalassemic patients on $\mathrm{HU}$.

One of the complications observed in patients treated with HU is cutaneous ulceration. In 2014, Crittenden and colleagues presented a case of a severe leg ulcer in an old woman with a history of myelodysplastic syndrome who has been on HU for 14 years, and homozygote for the C677T polymorphism of the methylene tetrahydrofolate reductase (MTHFR) gene, suggesting the implication of the MTHFR polymorphism or others thrombophilic genetic mutation in the development of cutaneous ulceration in patients on HU [57].

The above reports notwithstanding, little or no GWAS investigated association between genes encoding DME, especially those related to $\mathrm{HU}$ metabolism, and $\mathrm{HU}$ response (Table 1).

\section{Enzymatic reactions of hydroxyurea}

\section{Metabolism of HU in liver and kidney}

Currently, little is known about HU pharmacokinetics. It has been reported that approximately half of the drug is eliminated unchanged by the kidneys and the rest is metabolized in the liver [3]. Furthermore, it has been observed in mouse, that $30-50 \%$ of administered dose of $\mathrm{HU}_{-}{ }^{14} \mathrm{C}$ was found in the urine as urea- ${ }^{14} \mathrm{C}[58]$. It has also demonstrated that mouse liver and kidney would convert HU to urea [58]. In 1970, Colvin and Bono suggested an enzymatic reduction of the hydroxylamine group and demonstrated the enzymatic reduction of $\mathrm{HU}$ to urea catalyzed by mouse liver tissue in the hepatic mitochondria [59]. Huang and colleagues demonstrated the efficient formation of NO from HU mediated by enzymes present in crude rat liver homogenate [10].

\section{Potential enzymes involved in HU metabolism}

In humans, the metabolic pathways of $\mathrm{HU}$ have not been established [3]. Fishbein and colleagues in 1965 reported that Davidson and Winter observed the breakdown of $\mathrm{HU}$ to hydroxylamine, ammonia, and carbon dioxide when treated with urease (Fig. 3) [60]. Another work suggests that urease greatly enhanced $\mathrm{HbNO}$ formation and that $\mathrm{HU}$ is partially metabolized to hydroxylamine, which quickly reacts with $\mathrm{Hb}$ to form methhemoglobin (metHb) and $\mathrm{HbNO}[61,62]$. It has been shown that $50 \%$ of $\mathrm{HU}$ dose administered intraperitoneally was metabolized in liver and kidney tissue, suggesting that $\mathrm{NO}$ formation from $\mathrm{HU}$ occurs in the liver rather than the blood [10]. In addition to acting as a substrate for urease, HU can act as an inhibitor of this enzyme [63].

Hepatic microsomes contain monooxygenases, which may be separated into two groups, the cytochrome (s) P-448 inducible by polycyclic aromatic hydrocarbons and the cytochrome (s) P-450, which predominate in the liver and accept as substrates hydrophilic and non-planar compounds [16]. Hence, HU is susceptible to being metabolized by a 


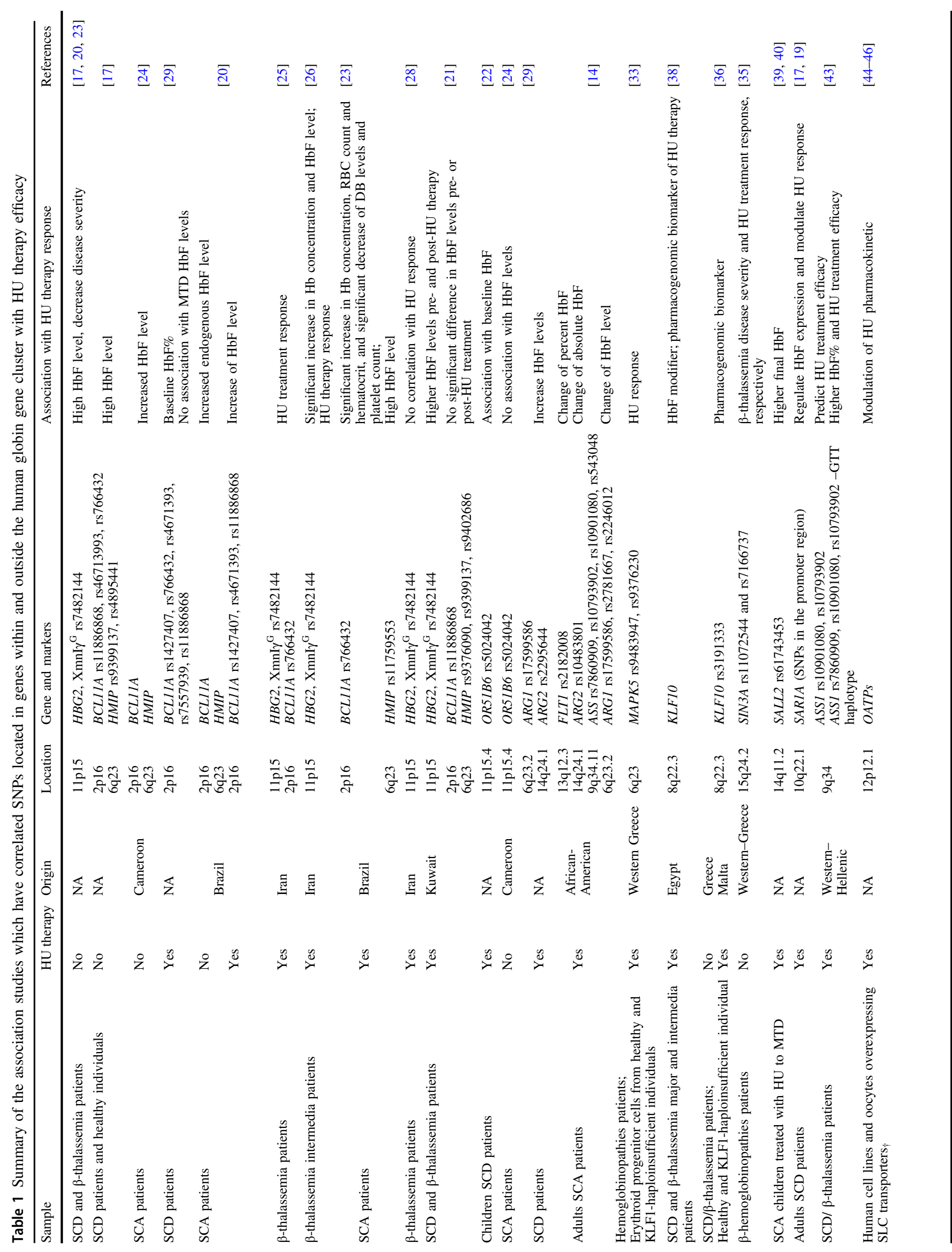




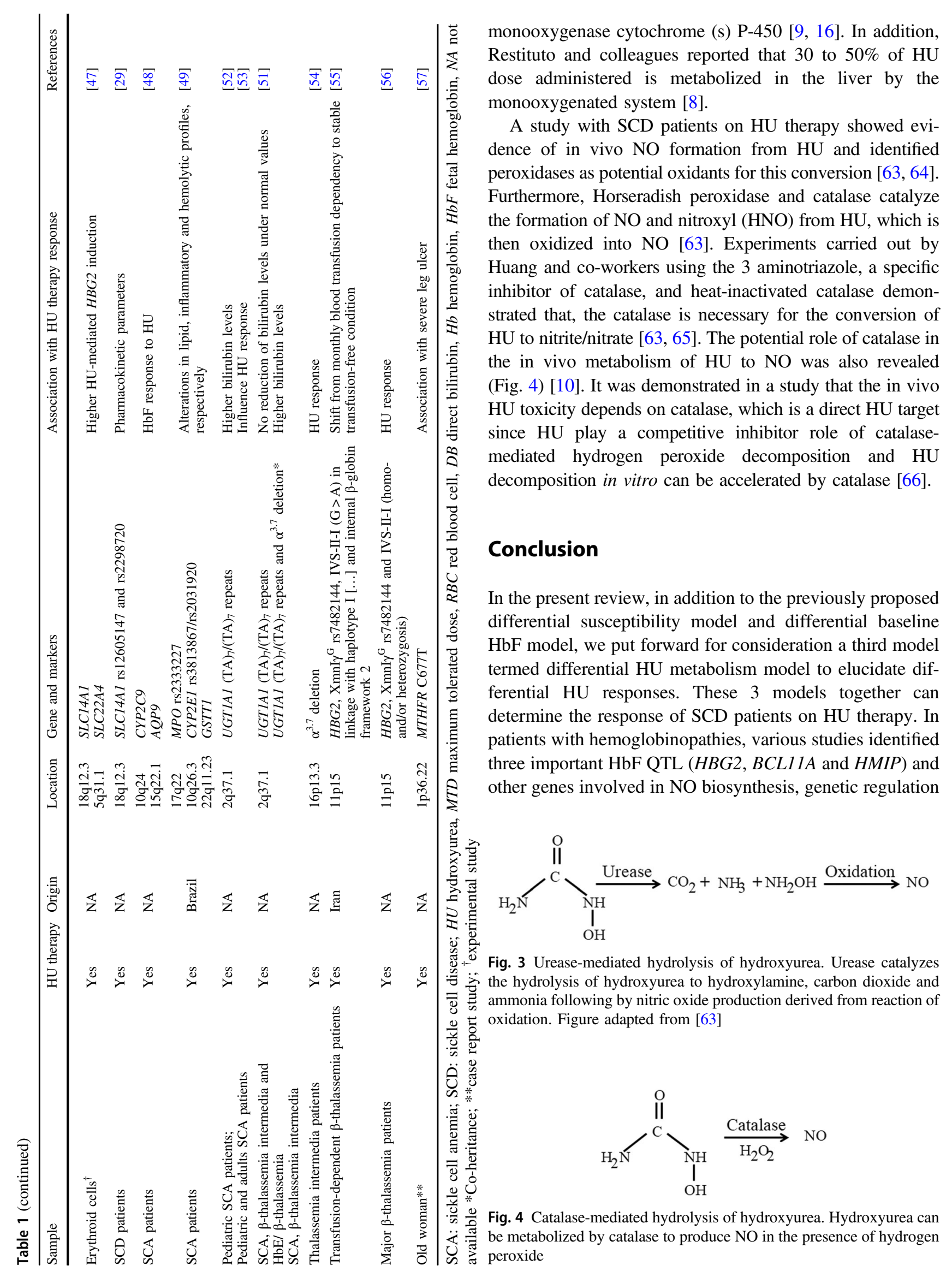


and drug metabolism (ASS1, KLF10, HAO2, MAP3K5, PDE7B, TOX, NOS1, NOS2A, FLT1, ARG1, ARG2, UGT1A1, OR51B5/6, SIN3A, SALL2, SAR1A, UTB, OCTN1, $C Y P 2 C 9, A Q P 9, M P O, C Y P 2 E 1$, and GSTT1). These genes considered as pharmacogenomic biomarkers can predict $\mathrm{HU}$ treatment efficacy. Despite the widespread use of HU and the diversity of its efficacy, the enzymes involved in its metabolic pathway are unknown. The few studies that investigated the enzymatic reactions of $\mathrm{HU}$, had suggested the participation of enzymes such as catalase, urease, horseradish peroxidase and enzymes of CYP450 family. Therefore, further studies are necessary to elucidate the metabolic pathway of $\mathrm{HU}$, which will allow identification and better selection of enzymes for pharmacogenomic studies in hemoglobinopathies patients under HU therapy.

\section{Compliance with ethical standards}

Conflict of interest The authors declare that they have no conflict of interest.

\section{References}

1. Villani P, Maserati R, Regazzi MB, Giacchino R, Lori F. Pharmacokinetics of hydroxyurea in patients infected with human immunodeficiency virus type I. J Clin Pharmacol. 1996;36:117-21.

2. Opacic N, Zorc B, Cetina M, Mrvos-Sermek D, Raic-Malic S, Mintas M. Synthesis and X-ray crystal structure study of the hydroxyurea and hydantoin derivatives of 1-valine. J Pept Res. 2005;66:85-93.

3. Dalton RN, Turner C, Dick M, Height SE, Awogbade M, Inusa B, et al. The measurement of urinary hydroxyurea in sickle cell anaemia. Br J Haematol. 2005;130:138-44.

4. Latagliata R, Spadea A, Cedrone M, Di Giandomenico J, De Muro M, Villivà $\mathrm{N}$, et al. Gruppo Laziale SMPC Ph1 neg. Symptomatic mucocutaneous toxicity of hydroxyurea in Philadelphia chromosomenegative myeloproliferative neoplasms: the Mister Hyde face of a safe drug. Cancer . 2012;118:404-9.

5. Lori F, Lisziewicz J. Rationale for the use of hydroxyurea as an anti-human immunodeficiency virus drug. Clin Infect Dis. 2000;30:S193-7.

6. Sassi H, Bachir D, Habibi A, Astier A, Galactéros F, Hulin A. No effect of CYP450 and P-glycoprotein on hydroxyurea in vitro metabolism. Fundam Clin Pharmacol. 2010;24:83-90.

7. Lori F, Malykh A, Cara A, Sun D, Weinstein JN, Lisziewicz J, et al. Hydroxyurea as an inhibitor of human immuunodeficiency virus type 1 replication. Sci New Ser. 1994;266:801-5.

8. Restituto P, Mugueta C, Alegre E, Monreal JI, Varo N. Analytical interference of hydroxyurea in the determination of urea, uric acid, and lactic acid. Anal Biochem. 2006;357:147-9.

9. King SB. The nitric oxide producing reactions of hydroxyurea. Curr Med Chem. 2003;10:437-52.

10. Huang J, Yakubu M, Kim-Shapiro DB, King SB. Rat livermediated metabolism of hydroxyurea to nitric oxide. Free Radic Biol Med. 2006;40:1675-81.

11. Kolliopoulou A, Stratopoulos A, Siamoglou S, Sgourou A, Ali BR, Papachatzopoulou A, et al. Key pharmacogenomic considerations for sickle cell disease patients. OMICS J Integr Biol. 2017;21:314-22.
12. Rees DC, Williams TN, Gladwin MT. Sickle-cell disease. Lancet. 2010;376:2018-31.

13. Silva-Pinto AC, Angulo IL, Brunetta DM, Neves FIR, Bassi SC, Santis GCD, et al. Clinical and hematological effects of hydroxyurea therapy in sickle cell patients: a single-center experience in Brazil. Sao Paulo Med J. 2013;131:238-43.

14. Ma Q, Wyszynski DF, Farrell JJ, Kutlar A, Farrer LA, Baldwin $\mathrm{CT}$, et al. Fetal hemoglobin in sickle cell anemia: genetic determinants of response to hydroxyurea. Pharm J. 2007;7:386-94.

15. Gravia A, Chondrou V, Sgourou A, Papantoni I, Borg J, Katsila T, et al. Individualizing fetal hemoglobin augmenting therapy for $\beta$ type hemoglobinopathies patients. Pharmacogenomics. 2014;15: 1355-64.

16. Andrae U. Evidence for the involvment of cytochrome P-450dependent monooxygenase(s) in the formation of genotoxic metabolites from N-hydroxyurea. Biochem Biophys Res Commun. 1984;118:409-15.

17. Banan M. Hydroxyurea treatment in $\beta$-thalassemia patients: to respond or not to respond? Ann Hematol. 2013;92:289-99.

18. Božina N, Bradamante V, Lovrić M. Genetic polymorphism of metabolic enzymes P450 (CYP) as a susceptibility factor for drug response, toxicity, and cancer risk. Arch Ind Hyg Toxicol. 2009;60:217-42.

19. Kumkhaek C, Taylor JG, Zhu J, Hoppe C, Kato GJ, Rodgers GP. Fetal haemoglobin response to hydroxycarbamide treatment and sarla promoter polymorphisms in sickle cell anaemia. Br J Haematol. 2008;141:254-9.

20. Friedrisch JR, Sheehan V, Flanagan JM, Baldan A, Summarell CCG, Bittar CM, et al. The role of BCL11A and HMIP-2 polymorphisms on endogenous and hydroxyurea induced levels of fetal hemoglobin in sickle cell anemia patients from southern Brazil. Blood Cells Mol Dis. 2016;62:32-7.

21. Adekile A, Menzel S, Gupta R, Al-Sharida S, Farag A, Haider M, et al. Response to hydroxyurea among Kuwaiti patients with sickle cell disease and elevated baseline $\mathrm{HbF}$ levels: $\mathrm{HU}$ among Kuwaiti patients with SCD. Am J Hematol. 2015;90:E138-E139.

22. Green NS, Ender KL, Pashankar F, Driscoll C, Giardina PJ, Mullen CA. et al. Candidate sequence variants and fetal hemoglobin in children with sickle cell disease treated with hydroxyurea. PLoS ONE. 2013;8:e55709.

23. Aleluia MM, Santiago RP, da Guarda CC, Fonseca TCC, Neves FI, Quinto RS, et al. Genetic modulation of fetal hemoglobin in hydroxyurea-treated sickle cell anemia. Am J Hematol. 2017;92: E70-E72.

24. Wonkam A, Ngo Bitoungui VJ, Vorster AA, Ramesar R, Cooper RS, Tayo B, et al. Association of variants at BCL11A and HBS1L-MYB with hemoglobin $\mathrm{F}$ and hospitalization rates among sickle cell patients in cameroon. PLoS One. 2014;9:e92506.

25. Banan M, Bayat H, Azarkeivan A, Mohammadparast S, Kamali K, Farashi S, et al. The XmnI and BCL11A single nucleotide polymorphisms may help predict hydroxyurea response in Iranian $\beta$ thalassemia patients. Hemoglobin. 2012;36:371-80.

26. Motovali-Bashi M, Ghasemi T. Role of XmnIgG polymorphism in hydroxyurea treatment and fetal hemoglobin level at Isfahanian intermediate $\beta$-thalassemia patients. Iran Biomed J. 2015;19: 177-82.

27. Ali N, Ayyub M, Khan SA, Ahmed S, Abbas K, Malik HS, et al. Frequency of $\mathrm{G} \gamma$-globin promoter $-158(\mathrm{C}>\mathrm{T}) \mathrm{XmnI}$ polymorphism in patients with homozygous/compound heterozygous beta thalassaemia. Hematol Oncol Stem Cell Ther. 2015;8:10-5.

28. Karimi M, Haghpanah S, Farhadi A, Yavarian M. Genotypephenotype relationship of patients with $\beta$-thalassemia taking hydroxyurea: a 13-year experience in Iran. Int $\mathrm{J}$ Hematol. 2012;95:51-6.

29. Ware RE, Despotovic JM, Mortier NA, Flanagan JM, He J, Smeltzer MP, et al. Pharmacokinetics, pharmacodynamics, and 
pharmacogenetics of hydroxyurea treatment for children with sickle cell anemia. Blood. 2011;118:4985-91.

30. Solovieff N, Milton JN, Hartley SW, Sherva R, Sebastiani P, Dworkis DA, et al. Fetal hemoglobin in sickle cell anemia: genome-wide association studies suggest a regulatory region in the $5^{\prime}$ olfactory receptor gene cluster. Blood. 2010;115: $1815-22$.

31. Akinsheye I, Solovieff N, Ngo D, Malek A, Sebastiani P, Steinberg $\mathrm{MH}$, et al. Fetal hemoglobin in sickle cell anemia: molecular characterization of the unusually high fetal hemoglobin phenotype in African Americans. Am J Hematol. 2012;87:217-9.

32. Cardoso GL, Diniz IG, Martins da Silva ANL, Cunha DA, da Silva Junior JS, Carvalho Uchôa CT, et al. DNA polymorphisms at BCL11A, HBS1L-MYB and Xmn1-HBG2 site loci associated with fetal hemoglobin levels in sickle cell anemia patients from Northern Brazil. Blood Cells Mol Dis. 2014;53:176-9.

33. Tafrali C, Paizi A, Borg J, Radmilovic M, Bartsakoulia M, Giannopoulou E, et al. Genomic variation in the MAP3K5 gene is associated with $\beta$-thalassemia disease severity and hydroxyurea treatment efficacy. Pharmacogenomics. 2013;14:469-83.

34. Atkins GB, Jain MK. Role of Kruppel-like transcription factors in endothelial biology. Circ Res. 2007;100:1686-95.

35. Gravia A, Chondrou V, Kolliopoulou A, Kourakli A, John A, Symeonidis A, et al. Correlation of SIN3A genomic variants with $\beta$-hemoglobinopathies disease severity and hydroxyurea treatment efficacy. Pharmacogenomics. 2016;17:1785-93.

36. Borg J, Phylactides M, Bartsakoulia M, Tafrali C, Lederer C, Felice $\mathrm{AE}$, et al. KLF10 gene expression is associated with high fetal hemoglobin levels and with response to hydroxyurea treatment in $\beta$ hemoglobinopathy patients. Pharmacogenomics. 2012;13:1487-500.

37. Kalra IS, Alam MM, Choudhary PK, Pace BS. Krüppel-like Factor 4 activates HBG gene expression in primary erythroid cells: KLF4 activates HBG gene transcription. Br J Haematol. 2011;154:248-59.

38. Elalfy MS, El Sherif NHK, Kamal TM, Aly NH. Klf10 gene, a secondary modifier and a pharmacogenomic biomarker of hydroxyurea treatment among patients with hemoglobinopathies. J Pediatr Hematol Oncol. 2017;39:e155-e162.

39. Sheehan VA, Crosby JR, Sabo A, Mortier NA, Howard TA, Muzny DM, et al. Whole exome sequencing identifies novel genes for fetal hemoglobin response to hydroxyurea in children with sickle cell anemia. PLoS One. 2014;9:e110740.

40. Pule GD, Mowla S, Novitzky N, Wiysonge CS, Wonkam A. A systematic review of known mechanisms of hydroxyurea-induced fetal hemoglobin for treatment of sickle cell disease. Expert Rev Hematol. 2015;8:669-79.

41. Tang DC, Zhu J, Liu W, Chin K, Sun J, Chen L, et al. The hydroxyurea-induced small GTP-binding protein SAR modulates gamma-globin gene expression in human erythroid cells. Blood. 2005;106:3256-63.

42. Karimi M, Zarei T, Haghpanah S, Moghadam M, Ebrahimi A, Rezaei N, et al. Relationship between some single-nucleotide polymorphism and response to hydroxyurea therapy in Iranian patients with $\beta$-thalassemia intermedia. J Pediatr Hematol Oncol. 2017;39:e171-e176.

43. Chalikiopoulou C, Tavianatou A-G, Sgourou A, Kourakli A, Kelepouri D, Chrysanthakopoulou M, et al. Genomic variants in the ASS1 gene, involved in the nitric oxide biosynthesis and signaling pathway, predict hydroxyurea treatment efficacy in compound sickle cell disease/ $\beta$-thalassemia patients. Pharmacogenomics. 2016;17:393-403.

44. Olives B, Neau P, Bailly P, Hediger MA, Rousselet G, Cartron JP, et al. Cloning and functional expression of a urea transporter from human bone marrow cells. J Biol Chem. 1994;269:31649-52.

45. Kobayashi D, Aizawa S, Maeda T, Tsuboi I, Yabuuchi H, Nezu J, et al. Expression of organic cation transporter OCTN1 in hematopoietic cells during erythroid differentiation. Exp Hematol. 2004;32:1156-62.

46. Walker AL, Steward S, Howard TA, Mortier N, Smeltzer M, Wang Y-D, et al. Epigenetic and molecular profiles of erythroid cells after hydroxyurea treatment in sickle cell anemia. Blood. 2011;118:5664-70.

47. Walker AL, Ofori-Acquah SF. Sustained enhancement of OCTN1 transporter expression in association with hydroxyurea induced $\gamma$ globin expression in erythroid progenitors. Exp Hematol. 2017;45:69-73.e2.

48. Wyszynski DF, Baldwin CT, Cleves M, Farrell JJ, Bisbee A, Kutlar A, et al. Genetic polymorphisms associated with fetal hemoglobin response to hydroxyurea in patients with sickle cell anemia. Blood. 2004;104:108.

49. SCMA Yahouédéhou, MOS Carvalho, Oliveira RM, Santiago RP, da Guarda CC, Carvalho SP, et al. Sickle cell anemia patients in use of hydroxyurea: association between polymorphisms in genes encoding metabolizing drug enzymes and laboratory parameters. Dis Markers. 2018;2018:1-11.

50. Joly P, Renoux C, Lacan P, Bertrand Y, Cannas G, Garnier N, et al. UGT1A1 (TA)n genotype is not the major risk factor of cholelithiasis in sickle cell disease children. Eur $\mathrm{J}$ Haematol. 2017;98:296-301.

51. Italia KY, Jijina FF, Jain D, Merchant R, Nadkarni AH, Mukherjee M, et al. The effect of UGT1A1 promoter polymorphism on bilirubin response to hydroxyurea therapy in hemoglobinopathies. Clin Biochem. 2010;43:1329-32.

52. Heeney MM, Howard TA, Zimmerman SA, Ware RE. UGT1A promoter polymorphisms influence bilirubin response to hydroxyurea therapy in sickle cell anemia. J Lab Clin Med. 2003;141:279-82.

53. Adekile A, Kutlar F, McKie K, Addington A, Elam D, Holley L, et al. The influence of uridine diphosphate glucuronosyl transferase 1A promoter polymorphisms, beta S-globin gene haplotype, co-inherited alpha-thalassemia trait and $\mathrm{Hb} \mathrm{F}$ on steady-state serum bilirubin levels in sickle cell anemia. Eur J Haematol. 2005;75:150-5.

54. Panigrahi I, Dixit A, Arora S, Kabra M, Mahapatra M, Choudhry VP, et al. Do alpha deletions influence hydroxyurea response in thalassemia intermedia? Hematology. 2005;10:61-3.

55. Yavarian M, Karimi M, Bakker E, Harteveld CL, Giordano PC. Response to hydroxyurea treatment in Iranian transfusiondependent beta-thalassemia patients. Haematologica. 2004;89: 1172-8.

56. Alebouyeh M, Moussavi F, Haddad-Deylami H, Vossough P. Hydroxyurea in the treatment of major beta-thalassemia and importance of genetic screening. Ann Hematol. 2004;83:430-3.

57. Crittenden SC, Gilbert JE, Callen JP. Hydroxyurea-induced leg ulceration in a patient with a homozygous MTHFR polymorphism misdiagnosed as pyoderma gangrenosum. JAMA Dermatol. 2014; 150:780.

58. Adamson RH, Ague SL, Hess SM, Davidson JD. The distribution, excretion and metabolism of hydroxyurea-C14. J Pharmacol Exp Ther. 1965;150:322-7.

59. Colvin M, Bono VH. The enzymatic reduction of hydroxyurea to urea by mouse liver. Cancer Res. 1970;30:1516-9.

60. Fishbein WN, Winter TS, Davidson JD. Urease catalysis: I. Stoichiometry, specificity, and kinetics of a second substrate: hydroxyurea. J Biol Chem. 1965;240:2402-6.

61. Jiang J, Jordan SJ, Barr DP, Gunther MR, Maeda H, Mason RP. In vivo production of nitric oxide in rats after administration of hydroxyurea. Mol Pharmacol. 1997;52:1081-6.

62. Lockamy VL, Huang J, Shields H, Ballas SK, King SB, KimShapiro DB. Urease enhances the formation of iron nitrosyl hemoglobin in the presence of hydroxyurea. Biochim Biophys Acta. 2003;1622:109-16. 
63. King SB. N-hydroxyurea and acyl nitroso compounds as nitroxyl (HNO) and nitric oxide (NO) donors. Curr Top Med Chem. 2005;5:665-73.

64. Gladwin MT, Shelhamer JH, Ognibene FP, Pease-Fye ME, Nichols JS, Link B, et al. Nitric oxide donor properties of hydroxyurea in patients with sickle cell disease. $\mathrm{Br} \mathrm{J}$ Haematol. 2002;116:436-44.
65. Huang J, Kim-Shapiro DB, King SB. Catalase-mediated nitric oxide formation from hydroxyurea. J Med Chem. 2004;47: 3495-501.

66. Juul T, Malolepszy A, Dybkær K, Kidmose R, Rasmussen JT, Andersen GR, et al. The in vivo toxicity of hydroxyurea depends on its direct target catalase. J Biol Chem. 2010;285:21411-5. 